\title{
Ameleorating the Effects of Variables that Contribute to Poor Performance in Mathematics of Candidates at Ordinary Level in Secondary Schools of Shurugwi District in Zimbabwe
}

\author{
Wilard Nyathi* \\ Faculty of Education: AMADI University
}

*Corresponding Author: Wilard Nyathi, Faculty of Education: AMADI University

\begin{abstract}
The study attempted to expose the major variables that contribute to low performance of candidates at Ordinary Level in Zimbabwean secondary schools with a specific objective of proffering mitigatory measures to address the phenomenon. The study revealed that most teachers faced resource, capacity and competency, constraints in their efforts to guide students in this subject. The streaming of pupils according to ability ranges also contributed to poor performance by students. The study also found that there was a general phobia for the subject by the school administrators as well as by the teachers and the students. The researcher recommends that there is need to adopt a multi-teaching style approach and staff development initiative to capacitate mathematics teachers. The study also recommends the abolition of streaming students as this promotes negative attitudes of the subject of the less gifted students as well as by the teachers.
\end{abstract}

Key words: Mitigate, low performance, candidates, ordinary level, negative factors, district.

\section{INTRODUCTION}

Mathematics is one of the most important school subjects in the school curriculum of any country across the globe, Guin, (2012), Umameh (2011), postulates that mathematics is the bedrock and an indispensable tool for scientific, technological and economic advancement of any nation. Mathematics relates to everything in the universe from the smallest to the largest Mefor, (2014). The study of mathematics provides one with the skills and abilities required in our daily lives, Chirume, (2012). It is through studying mathematics that one gets to appreciate probability, time, interests, discounts, rates of exchange, money calculations and ratios among other equally important concepts that we came across in our daily lives, (Chiramba, 2016).

Ale and Lawal (2010) stated that the line of demarcation between the developed and the underdeveloped nations is based on their level of mathematical attainment and ingenuity. Nosa and Ohenhen (1998), concerned with this perception and stated that evidence about to show that nations that embrace mathematics, science and technology enjoy better standard of living and are less dependent on others, Mefor (2014), commenting on the importance of mathematics helps the mind to reason and organise complicated situations or problems into clear, simple and logical steps. The reality is that in any society, high paying jobs often demand someone who can simplify complicated situations and reduce them to the level everyone can understand (Mefor, 2014). Therefore, this means that by knowing more mathematics, students give themselves the competitive edge they need to vie for such high paying jobs, Skemp, (2008).

Unfortunately, students' performance in this all important subject has been consistently poor in the Ordinary level certificate in Zimbabwe. Ordinary level is the examination written by Zimbabwean students at the end of their four years at secondary school, and it is used to measure the extent of knowledge and skills the students have acquired at that level of education. The result of this examination is also used as pre-requisite for admission into Advanced level, tertiary institutions and professions like teaching, nursing and many others. In most Zimbabwean institutions, a credit pass in Mathematics and English Language is required. However, students' examinations at Ordinary level show a steady trend of mass failure of students in mathematics. The Zimbabwe School Examinations Council (ZIMSEC) results analysis from 2014 to 2019 reveal that the percentage pass rate in 
Ameleorating the Effects of Variables that Contribute to Poor Performance in Mathematics of Candidates at Ordinary Level in Secondary Schools of Shurugwi District in Zimbabwe

mathematics at Ordinary level within this period did not reach fifty percent $(50 \%)$ as shown in the table below.

\begin{tabular}{|c|c|}
\hline Year & \% Percentage Pass Rate \\
\hline 2014 & 13,91 \\
\hline 2015 & 18,515 \\
\hline 2016 & 10,65 \\
\hline 2018 & 20,79 \\
\hline 2019 & 32,28 \\
\hline
\end{tabular}

Source. ZIMSEC (2018)

Although the results reveal an upward movement of the figures, this trend is still a great cause for consternation because in 2017 with the highest percentage pass rate, 63 percent of the country's candidates who sat for the mathematics paper failed. It therefore, comes as no surprise that the mathematics paper is one of a few that always experience leakages as teachers and pupils find shortcuts of trying to pass the subject, Nhandara, (2018).

It was on the basis of the information above that the researcher exposed the major variables that contribute to this high failure rate with the aim pf proffering mitigatory measures.

\section{Statement of the Problem}

In spite of the significant role that mathematics plays in the lives of the people, the high failure rate mean that those students who do not possess the subject in the Ordinary level certificates will find it very difficult to advance with their education or take up professional courses of their choice. The need to come up with concrete suggestions to curb this scourge cannot be overemphasized.

\section{Purpose OF THe STUdy}

The purpose of this empirical study was to expose the major variables that contribute towards the low performance of candidates at Ordinary level and come with measures that can be adopted to mitigate the situation.

\section{SignificanCE OF THE STUdY}

The importance of this study stems from the fact that if the major variables contributing to students' failure are exposed and mitigated, this is most likely to help the learners, the teachers and the parents as well as the other stakeholders to have empirical evidence to tackle the problem. The study also envisages to sensitize about the need to improve the teaching and learning conditions for the subject for the development of the country.

\section{RESEARCH METHODOLOGY}

The study used the mixed methods methodology. As Terrel (2012) postulates, many social scientists assert that there are no major areas of inquiry that should be studied exclusively with one form of research methodology. Quantitative typically explains the "if" and qualitative the "why" Terrel, (2012). Therefore, mixed methods have been described as the unifying research paradigm to join these two elements (Johnson: 2014). The study benefitted immensely from this paradigm because it utilized the strengths or quantitative and qualitative approaches, while minimizing their limitations. As Cresswell, (2014), posits, at a practical level, mixed methods provide a complex and sophisticated approach and it is very appealing for researchers at the forefront of new research procedures. Similarly, at procedural level, it is a useful strategy to understand research problems by comparing different perspectives from qualitative and quantitative data as well as developing an understanding of experimental results by incorporating the perspectives of individuals, Cresswell, (2014). The triangulation design was used to collect and generate the data.

The target population were all the secondary school heads, deputy heads, heads of departments, mathematics teachers and pupils at Shurugwi District in the Midlands Province in Central Zimbabwe. The accessible population constituted ten (10) secondary schools purposively selected because they had more than two mathematics teachers. The sample composed of ten (10) heads of schools, ten (10) deputy heads, ten (10) heads of departments from the sciences department, two (2) teachers from each 
school giving a total of twenty (20) teachers as well as five (5) pupils from each school, making a total of fifty (50) pupils, made up of twenty-five (25) girls and twenty-five (25) boys. Altogether, there were one hundred (100) respondents and participants. The questionnaire was used to collect quantitative data and the interview used for the qualitative data.

\section{LiTERATURE REVIEW}

Developing nations are characterized by not so well trained teachers. Skemp (2008) postulates that the majority of these teachers lack the pedagogical knowledge that makes them to become effective and competent teachers in most subjects. Teachers without proper qualifications and likely to fail to interpret what is required by the set curriculum to help learners understand all the concepts. At some instances, they may simply evade the teaching of certain concepts that may be equally challenging to them, Chirume, (2012). Other instances may see them having to give an overdose of information or techniques to the pupils which may not be necessary at that level, Kitta, (1997).

The other problem is the nature of the materials prepared for mathematics teaching and learning. As Mefor (2014), states, the syllabus emphasizes learner-centred approached and ye the curriculum materials used particularly the textbooks, do not reflect learner centredness. They focus more on the content, with little emphasis on the pedagogy. In the teaching of mathematics, there has been a huge gap between the intended curriculum and the attained curriculum (Marsh and Williams.......)

According to Alicke (2000), the authoritarian teacher is another factor that contributes to poor performance of learners in mathematics just as in other subjects. The authoritarian teacher gives no room for the exchange of ideas but rather imposes his/her view on what he/she feels is like correct method to use when working out given sums such as simultaneous equations Hanslam, (2004). Ale and Lawal (2010), pointed to the significance of the notion of curricular pace as a critical variable affecting achievement in mathematics, hence it need to be moderated to suit the calibre of pupils/learners at hand. As Skemp (2008) posits, to talk of mathematics for all entails an intention to change general attitudes towards mathematics as a subject, to slow the pace of teaching, to eliminate divisions between those who are friends of mathematics and those who are not, and to diminish variance in the achievement outcomes of mathematics teaching.

\section{FINDINGS AND DISCUSSIONS}

The study set out to establish the negative factors that contribute towards low performance of ordinary level candidates in mathematics in Zimbabwean secondary schools. This section is presented in two parts; namely, presentation of data and discussion thereof.

\subsection{Presentation of Data}

\section{Composition of sample by sex}

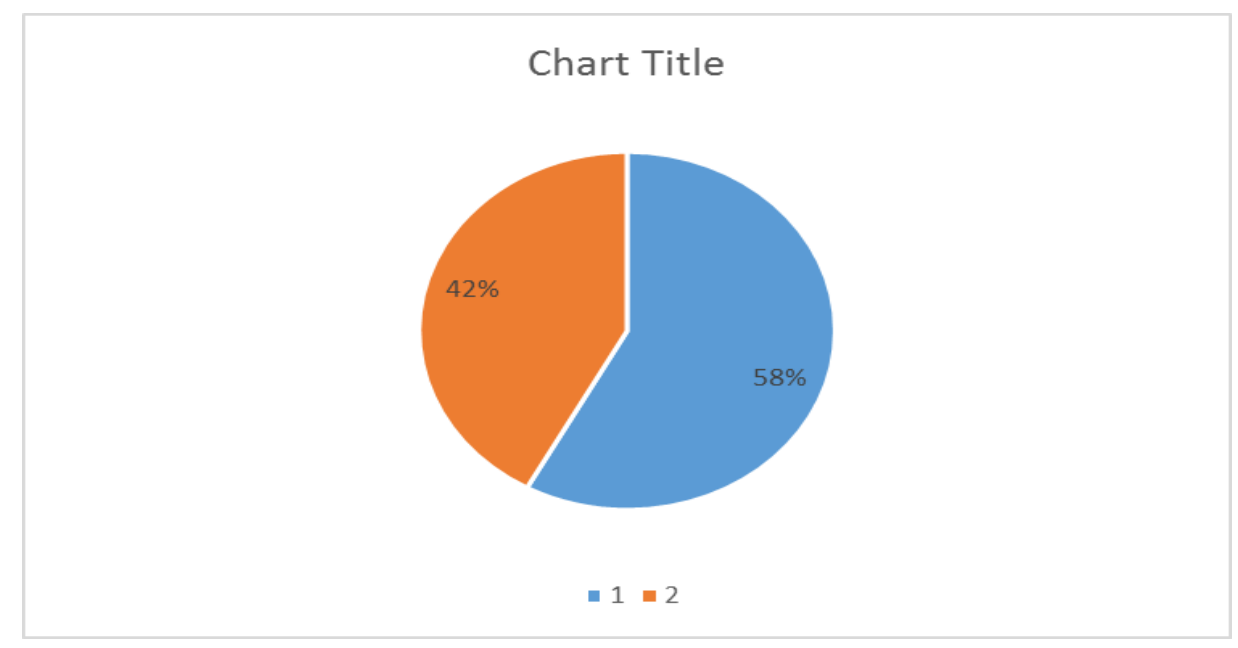

Figure1. Distribution of sample by sex $(N=100)$

The data on figure 1 above reveals that there were more males in the sample, (58\%) than females $(42 \%)$. There was an equal number of pupils in the sample (that is twenty-five (25) of each), which 
Ameleorating the Effects of Variables that Contribute to Poor Performance in Mathematics of Candidates at Ordinary Level in Secondary Schools of Shurugwi District in Zimbabwe

means that the disparities in the percentage composition emanated from the heads, deputy heads, heads of departments as well as mathematics teachers. This means that there were more male heads, deputy heads, heads of departments and mathematics in the study than the female ones, (33\% against $17 \%$ respectively). The significance of this statistics as far as this study is concerned is that school administrators and mathematics teachers are predominantly male.

\section{Composition of sample by status}

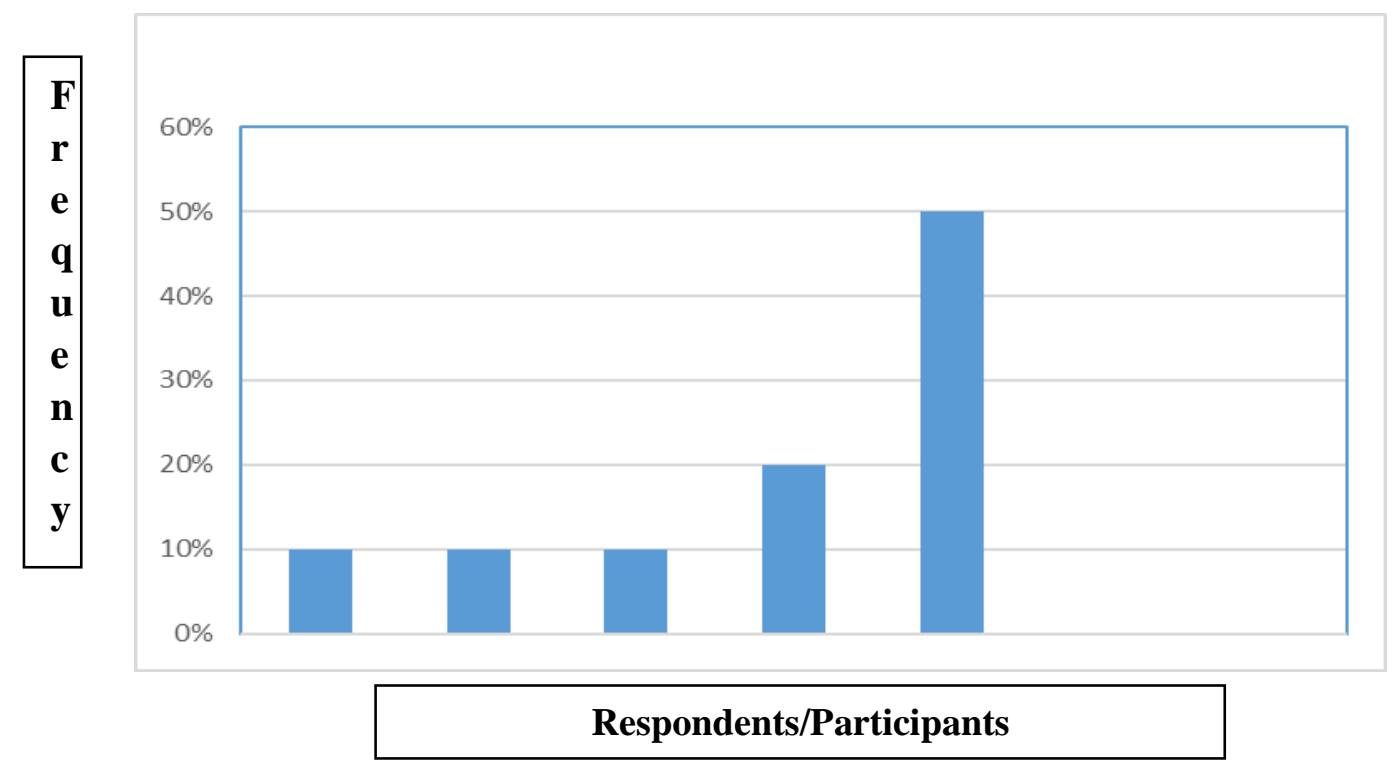

Heads Deputy Head of Maths Pupils Heads Department Teachers

Figure2. Distribution of sample by status $(N=100)$

The information above shows that a wide spectrum of relevant stakeholders was involved in the study. This eliminated bias and provided a somewhat true picture of the actual footing in each respective school are to the checks and balances enhanced in each case, technically referred to as triangulation.

Table1. Highest Mathematics qualifications for the heads, deputy heads, heads of department and teachers $(N=50)$

\begin{tabular}{|l|l|l|l|l|l|l|}
\hline Category & 'O' Level & 'A' Level & First & Master' & No maths & Totals \\
\hline Heads & 4 & 1 & 0 & 0 & 5 & $\mathbf{1 0}$ \\
\hline Deputy Heads & 7 & 1 & 1 & 0 & 2 & $\mathbf{1 0}$ \\
\hline Heads of Departments & 4 & 4 & 2 & 0 & 0 & $\mathbf{1 0}$ \\
\hline Teachers & 12 & 6 & 2 & 0 & 0 & $\mathbf{2 0}$ \\
\hline Totals & $\mathbf{2 7}$ & $\mathbf{1 2}$ & $\mathbf{5}$ & $\mathbf{0}$ & $\mathbf{7}$ & $\mathbf{5 0}$ \\
\hline
\end{tabular}

Table 1 above reveals that half the number of heads in the sample did not possess mathematics as only 4 had mathematics at Ordinary level and 1 at Advanced level. As for deputy heads, the bulk of the 10 also had mathematics at Ordinary level (7) and 1 apiece at Advanced level and first degree level. All the heads of departments had a mathematics qualification, but only 2 had first degrees on the subject. All the teachers teaching the subject were in possession of the subject.

Table2. Teaching experience of mathematics by the heads, deputy heads, heads of departments and teachers $(N=100)$.

\begin{tabular}{|l|l|l|l|l|l|l|}
\hline Category & $\mathbf{0}-\mathbf{5}$ years & $\mathbf{6 - 1 0}$ years & $\mathbf{1 1}$-15 years & $\mathbf{1 6}$ years & Never taught & Totals \\
\hline Heads & 1 & 0 & 0 & 0 & 9 & $\mathbf{1 0}$ \\
\hline Deputy Heads & 0 & 2 & 0 & 0 & 8 & $\mathbf{1 0}$ \\
\hline Heads of Departments & 6 & 1 & 1 & 2 & 0 & $\mathbf{1 0}$ \\
\hline Teachers & 14 & 2 & 2 & 2 & 0 & $\mathbf{2 0}$ \\
\hline Totals & $\mathbf{2 1}$ & $\mathbf{5}$ & $\mathbf{3}$ & $\mathbf{4}$ & $\mathbf{1 7}$ & $\mathbf{5 0}$ \\
\hline
\end{tabular}

The data above shows that from the heads and deputy head's side, 9 out of 10 heads had never taught mathematics while 8 out of 10 deputy heads had never taught the subject. All the heads of departments have teaching experience in the subject. The majority of the heads of departments had less than 6 years of teaching the subject. Most of the teachers had less than 6 years of teaching mathematics. 
Ameleorating the Effects of Variables that Contribute to Poor Performance in Mathematics of Candidates at Ordinary Level in Secondary Schools of Shurugwi District in Zimbabwe

Table3. Major causes of failure by students in mathematics $(N=100)$

\begin{tabular}{|l|l|l|l|l|}
\hline Causes of failure & To a greater extent & To a lesser extent & To no extent & Totals \\
\hline Lack of proper qualifications & 65 & 10 & 25 & 100 \\
\hline Adopted teaching style & 70 & 15 & 15 & 100 \\
\hline Streaming/Ability grouping & 80 & 5 & 15 & 100 \\
\hline Lack of interest by pupils & 77 & 11 & 12 & 100 \\
\hline Lack of support from administration & 86 & 4 & 10 & 100 \\
\hline Lack of proper infrastructure & 67 & 24 & 9 & 100 \\
\hline Lack of resources & 89 & 1 & 10 & 100 \\
\hline
\end{tabular}

The information above (Table 3) reveals that a number of factors were attributed to the failure of students in mathematics. These include lack of support from the administration, streaming of pupils, teaching styles, lack of proper infrastructure to teach the subject as well as lack of proper qualifications by teachers and administrators.

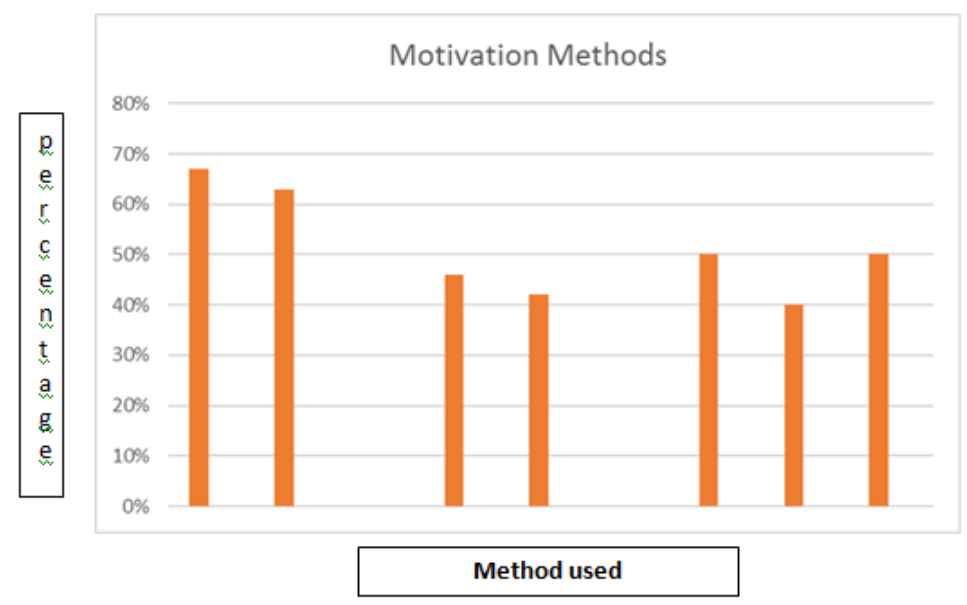

Reinforcing Using Varying Giving Providing Offer Knowing with reaching teaching frequent individuals. Incentives each positive aids methods feedback attention to any student comments small by name progress

Figure3. Methods used by mathematics teachers to motivate students

Sixty-seven percent $(67 \%)$ of the teacher respondents always reinforced student with positive comments to help them improve their attitude towards learning and performance in mathematics. Sixty-three percent $(63 \%)$ used teaching aids very often to enhance students understanding of the topics being taught. In addition, varying teaching methods were always adopted by $46 \%$ of the respondents. Forty-two percent (42\%) always gave frequent feedback to students on questions and exercises done to help them know answers and enhance their understanding of the content. Providing individual attention was often adopted by $50 \%$ of the respondents and was aimed at addressing student' specific weakness in learning the subject.

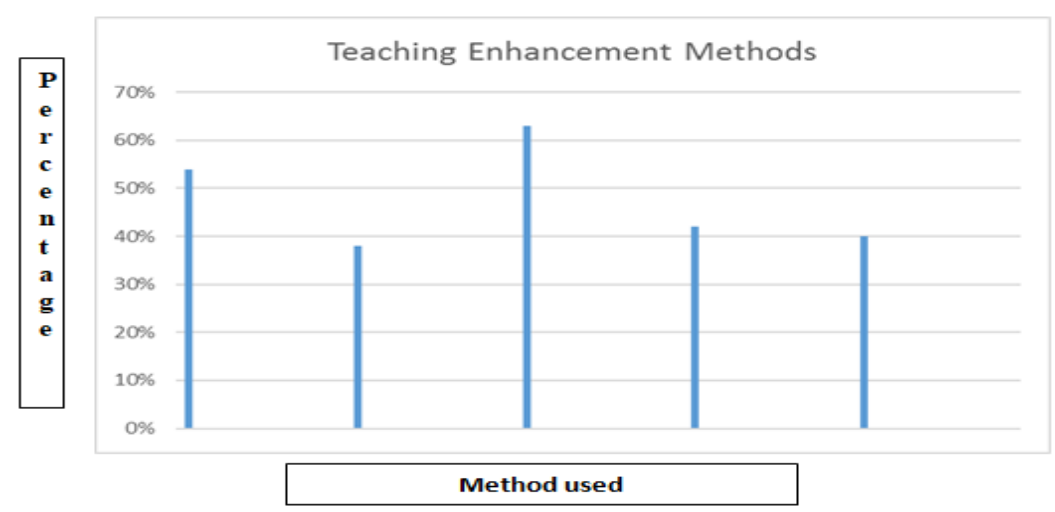

Small Student to Teacher Question Lecture group student assisting and method discussion demonstration individual answer

Figure4. Methods used in teaching to enhance learning of mathematics 
Small group discussion was often used according to fifty-four (54\%) of the respondents while student to student demonstration was often used by thirty-eight $(38 \%)$ of the teachers. Teacher assisting individual student was adopted by sixty-three percent (63\%) of the respondents while question and answer very often used by forty-two percent ( $42 \%)$ of the respondents.

Students seemed to like the subjects more when they worked in small group discussion as well as when given individual attention by their teachers to enable them to clearly understand the concepts as stated earlier. According to approximately, forty-percent (40\%) of teachers under the study, the students did not like the lecture method which was not participatory by nature. Increased cooperation of the students in class was attributed to the teacher's friendly attitude where teachers gave the students chance to ask questions on aspects they did not seem to understand and demonstrating the application of the subject in everyday life especially when the teachers asked them more challenging questions in questions and answers sessions.

\subsection{Discussion}

Most heads, deputy heads, heads of departments and mathematics teachers were male. This means that school leadership is still a preserve of males in this district. This tallies with studies by Ndlovu (2016) who found that despite the fact that women teachers constitute more than fifty-two percent (52\%) of the teacher population, in terms of leadership and management positions, they were not visible. In terms of head of departments and mathematics teachers, this revealed that mathematics was still a preserve of males in schools as females were not occupying teaching posts in the subject.

Data also reveal that most heads did not possess mathematics in any of their qualifications. The highest qualification in the few who had mathematics was Ordinary level. The same situation applied to the deputy heads. They too only had mathematics at Ordinary level. As Mefor (2014) argues, when curriculum leaders are themselves not sure about any subject offered by their institutions, it becomes very difficult for the teachers and learners to get the necessary guidance and motivation on that subject. Most of the heads and deputy heads had never taught mathematics throughout their careers as teachers. This made it quite challenging for them to go unto mathematics classrooms and confidently and effectively observe teachers teach this subject. Jones (2008), stated that the phobia for mathematics in the schools started from the head's office running down right up to the learners.

The information from the study also revealed that the major challenges experienced in the teaching and learning of mathematics revolved around lack of resources that include infrastructure, text books and other materials to complement the teaching and learning of the subject. The lack of motivation to teach, teaching style, mixed learner abilities, conflicting approaches as well as lack of interest and motivation to learn also affected the teaching and learning of mathematics. This tallies with findings by Ale and Lawal (2010) who states that, most mathematics teachers are very shallow in the mathematics content to be able to help learners fully comprehend the subject.

Data also reveal that teachers did not use proper motivation and enhancement methods and strategies to simplify content for the learners. Very few cases of use of teaching/learning aids were found. Teachers did not vary their teaching methods; neither did they use proper enhancement methods. This is corroborated by findings by Chiramba (2016) who argues that;

It's not enough to know a lot of mathematics.

A good teacher must also understand how

students are thinking about mathematics and

how to structure instructional opportunities to

support their learning.

\section{CONCLUSiON}

Based on the findings of this study, the researcher makes the following conclusions. School authorities should be aware that there are certain aspects of students' learning in mathematics that need intensive attention. Students should be given more opportunities to work on non-routine and challenging mathematics problems and this will require teachers to go the extra mile in leading students, that students' negative attitudes towards mathematics is enhanced by lack of leadership from 
the school in this subject. The school heads and their deputies lack the basic competencies in the subject that would motivate them to lead by example and yet they seem to be leading in the fear and anxiety towards the subject. Schools also lack proper resources for effective teaching of this subject.

\section{RECOMMENDATIONS}

The following recommendations are provided by this study based on the findings and conclusions above.

- Positive attitudes towards learning and performing well in mathematics are necessary performing well in mathematics ingredients in secondary school mathematics education. There is need for school authorities to lead by example in motivating pupils to do mathematics.

- There is need to provide materials and other resources to facilitate learning and teaching of mathematics by pupils and teachers. The Government should come up with various initiatives to build special mathematics classrooms and laboratories in all the schools to promote proper learning of the subject, just as there are specialist classrooms for other critical subjects like science, home economics among others.

- Teachers should vary teaching methods and styles instead of overreliance on one method in order to motivate learners by making the subject more interesting.

- Streaming should be avoided in this subject as it forces teachers to concentrate on able learners thereby abandoning those in low aptitude classes.

- School administrators should hold regular school symposiums to reinforce the importance of the subject.

- More females should be encouraged to take up teaching posts in mathematics to act as role models for the female candidates.

\section{ACKNOWLEDGEMENTS}

The author would like to thank Dr. Khosa for proof-reading and providing guidance on language quality. The author would also like to thank Mr Mudzamiri who was my assistant researcher. I would like also to thank the Ministry of Primary and Secondary Education for allowing me to conduct my study in their schools.

\section{REFERENCES}

[1] Ale, S. and Lawal, A. (2010). The National Mathematical Centre and the Mathematics Improvement Project in Nation Building. Journal of Mathematical Sciences, (1) 1-19

[2] Alicke, M.D. (2000), Culpable Control and the Psychology of Blame. Psychological Bulletin, 126, 556574

[3] Chiramba, L. (2016), Doing Mathematics in Zimbabwean Schools. Harare College Press

[4] Chirume, S. (2012), The Zimbawe 'O' Level Mathematics Curriculum and Students' Career Aspirations in Shurugwi and Gweru Districts. Harare, Zimbabwe Open University

[5] Cresswell, J.W. (2009), Research Design: Qualitative, Quantitative, and Mixed Methods Approaches, London, Sage.

[6] Guin, D. (2012), Instrumentation in Mathematics Education. International Journal of Computers for Mathematica Learning, 3(3):195-227

[7] Johnson, J. (2014), Research for Social Sciences, London, Longman

[8] Kitta, S. (1997), Science and Mathematics Teachers' Perceptions about Peer Coaching in Tanzania Enschede: University of Twente.

[9] Mefor, C. (2014), Nigeria: Identifying Problems of Poor Performance in Mathematics and Way out, Njoro: Egerton University Press.

[10] Ndlovu, P. (2016), Teaching Mathematics for Passing, Harare, ZPH

[11] Nhandara, E. (2018), June 2015 Ordinary level Results, Harare, Zimpapers.

[12] Ohenhen, N.D. (1998). Science, Technology and Mathematics: The Tools for Technological Development in Nigeria, Journal of Education, 3(1): 350-356 
Ameleorating the Effects of Variables that Contribute to Poor Performance in Mathematics of Candidates at Ordinary Level in Secondary Schools of Shurugwi District in Zimbabwe

[13] Skemp, R.R. (2008), the Psychology of Learning Mathematics, Hillside: Lawrence Eribaum Associates.

[14] Terrel, M. (2012), Mixed Methods Research Methodologies, New York: Teacher College Pres

[15] Umameh, H. (2011), Survey of Students' Poor Performance in Mathematics, Lagos: Longman

[16] ZIMSEC (2017), Analysis of Ordinary Level Results, Harare Zimpapers

\section{AUTHORS' BIOGRAPHY}

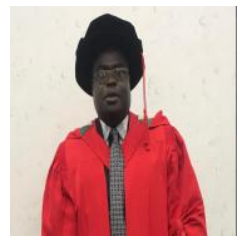

Dr Wilard Nyathi, an academic, administrator, manager and an author. A holder of a $\mathrm{PhD}$ in educational leadership, Management and policy development, $\mathrm{M}$ Ed in educational leadership and Management, MBA in business leadership and Management, B Ed Management, Diploma in education and Diploma in Information Technology

Citation: Wilard Nyathi. "Ameleorating the Effects of Variables that Contribute to Poor Performance in Mathematics of Candidates at Ordinary Level in Secondary Schools of Shurugwi District in Zimbabwe" International Journal of Humanities Social Sciences and Education (IJHSSE), vol 7, no. 9, 2020, pp. 112-119. doi: https://doi.org/10.20431/2349-0381.0709011.

Copyright: (C) 2020 Authors. This is an open-access article distributed under the terms of the Creative Commons Attribution License, which permits unrestricted use, distribution, and reproduction in any medium, provided the original author and source are credited. 